\title{
$\mathrm{DC} / \mathrm{DC}$ 강압컨버터의 $\mathrm{PWM}-\mathrm{IC}$ 제어기의 TID 및 SEL 실험
}

노영환*, 황의성*, 정재성**, 한창운**

\section{TID and SEL Testing on PWM-IC Controller of DC/DC Power Buck Converter}

\author{
Young Hwan Lho*, Eui Sung Hwang*, Jae-Seong Jeong** and Changwoon Han** \\ Department of Railroad Electricity System, Woosong University*, KETI**
}

\begin{abstract}
DC/DC switching power converters are commonly used to generate a regulated DC output voltage with high efficiency. The DC/DC converter is composed of a PWM-IC (pulse width modulation-integrated circuit) controller, a MOSFET (metal-oxide semiconductor field effect transistor), inductor, capacitor, etc. It is shown that the variation of threshold voltage and the offset voltage in the electrical characteristics of PWM-IC increase by radiation effects in TID (Total Ionizing Dose) testing at the low energy $\mathrm{\gamma}$ rays using ${ }^{60} \mathrm{Co}$, and 4 heavy ions applied for SEL (Single Event Latch-up) make the PWM pulse unstable. Also, the output waveform for the given input in the DC/DC converter is observed by the simulation program with integrated circuit emphasis (SPICE). TID testing on PWM-IC is accomplished up to the total dose of $30 \mathrm{krad}$, and the cross section $\left(\mathrm{cm}^{2}\right)$ versus $\mathrm{LET}\left(\mathrm{MeV} / \mathrm{mg} / \mathrm{cm}^{2}\right)$ in the PWM operation is studied at SEL testing after implementation of the controller board.
\end{abstract}

\section{초 록}

$\mathrm{DC} / \mathrm{DC}$ 컨버터는 임의의 직류전원을 부하가 요구하는 형태의 직류전원으로 변환시키는 효율이 높은 전력변환기이다. DC/DC 컨버터는 PWM-IC(펄스폭 변조 집적회로) 제어기, $\operatorname{MOSFET(ㅅㅏㄴㅎㅘㅁㅜㄹ-ㅂㅏㄴㄷㅗㅊㅔ~ㅈㅓㄴㄱㅖ~ㅎㅛㄱㅘ~ㅌㅡㄹㅐㄴㅈㅣㅅㅡㅌㅓ),~ㅇㅣㄴㄷㅓㄱㅌㅓ,~ㅋㅗㄴㄷㅔㄴㅅㅓ~ㄷㅡㅇㅇㅡㄹㅗ~ㄱㅜㅅㅓㅇㄷㅚㅇㅓㅇㅣㅆㄷㅏ.~ㅋㅗㅂㅏㄹ~}$ 트 $60\left({ }^{60} \mathrm{Co}\right)$ 저준위 감마발생기를 이용한 TID실험에서 방사선의 영향으로 PWM-IC의 전 기적 특성중에 문턱전압과 옵셋전압이 증가되고, $\mathrm{SEL}$ 에 적용된 4 종류의 중이온 입자는 PWM-IC의 파형을 불안정하게 만든다. 또한, 입/출력관계의 파형을 SPICE 시뮬레이션 프 로그램으로 관찰하였다. PWM-IC의 TID 실험은 $30 \mathrm{Krad}$ 까지 수행하였으며, SEL 실험을 제어보드를 구현한 후 $\operatorname{LET}\left(\mathrm{MeV} / \mathrm{mg} / \mathrm{cm}^{2}\right)$ 별 $\operatorname{cross} \operatorname{section}\left(\mathrm{cm}^{2}\right)$ 으로 연구하였다.

Key Words : DC/DC buck converter(강압 컨버터), radiation effects(방사선 영향), PWM-IC, TID, SEE, SEL

I. 서 론

다목적실용위성 3호에서 개발하고 있는 DC-DC 컨버터에 사용되는 반도체 소자는
MOSFET, PWM-IC, OP-Amp. MOSFET DriverIC, Oscillator, Diode 등이 사용된다. MOSFET는 입력 측에서 출력 측으로 전달되는 에너지를 제 어하는 기능을 하며, 인덕터와 커패시터는 에너
† Received: September 1, 2012 Accepted: December 31, 2012

* Corresponding author, E-mail : yhlho@wsu.ac.kr http://journal.ksas.or.kr/

pISSN 1225-1348 / eISSN 2287-6871 


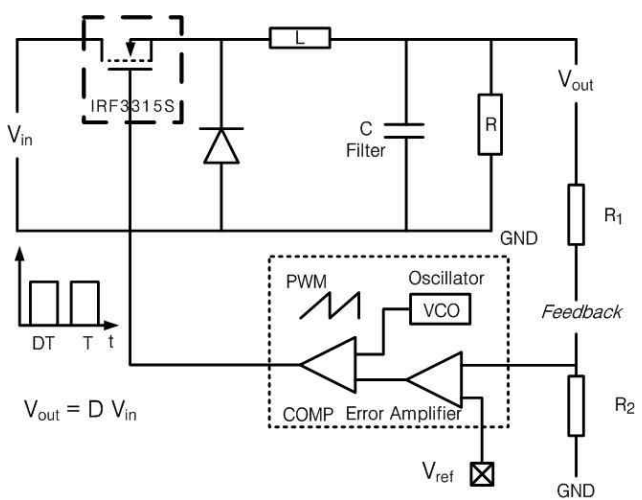

Fig. 1. Block Diagram of Buck Converter

지를 전달하는 기능을 하거나 출력전압의 리플 (ripple)을 제거하기 위해 필터 역할을 한다. 강 압컨버터에서 출력전압 $\left(V_{o}\right)$ 과 입력전압 $\left(V_{i}\right)$ 사이 에 관계는 등식 (1)과 같이 출력전압은 입력전압 에 비례한다.

$$
V_{o}=D V_{i}
$$

여기서 $\mathrm{D}$ 는 통류율(duty ratio)이고 값은 0 에서 1 까지이다. 출력전압은 평균전압이 $D V_{i}$ 인 직류성 분 외에 구형파의 교류성분이 가미되어 있으나, 대체적으로 부하에서 필요로 하는 전원은 일정한 직류전원이므로 출력전원에 포함된 불필요한 교 류성분을 제거해 주어야 한다. 이를 위해 출력의 직류성분은 통과시키고, 교류성분은 차단하는 저 역필터(low pass filter)회로가 필요하다. 강압컨 버터에서 인덕터 $L$ 과 커패시터 $C$ 가 이상적으 로 매우 크면 정상상태에서 인덕터 $L$ 에는 일정 한 전류가 흐르고 커패시터 $C$ 양단에는 일정한 전압이 걸린다. 그러나 실제로 인덕터와 커패시 터는 이상적이지 않으므로 인덕터 전류와 커패시 터 전압은 리플성분이 포함되어 있다. Fig. 1의 IRF3315은 항복전압(breakdown voltage)이 150 $\mathrm{V}$ 이고 문턱전압(threshold voltage $\left.\left(V_{t h}\right)\right)$ 이 3.0 $\mathrm{V}$ 인 IR(International Rectifier)사의 MOSFET이 다. $\mathrm{DC} / \mathrm{DC}$ 컨버터의 핵심부품인 $\mathrm{PWM}[1,2]$ 동 작 상태를 검증하기 위해 Fig. 2와 같이 $\mathrm{UC}$ 2846[3] 의 PWM-IC 회로도를 설계하였다.

\section{II. $\mathrm{DC} / \mathrm{DC}$ 컨버터의 동작원리}

\subsection{PWM-IC의 구동}

PWM-IC의 동작을 확인시키기 위해 Fig. 2의 $\mathrm{PWM}-\mathrm{IC}$ 의 블록도에서 출력전압의 크기는 펄스 의 폭에 따라 선형적으로 정해진다. 연산증폭기

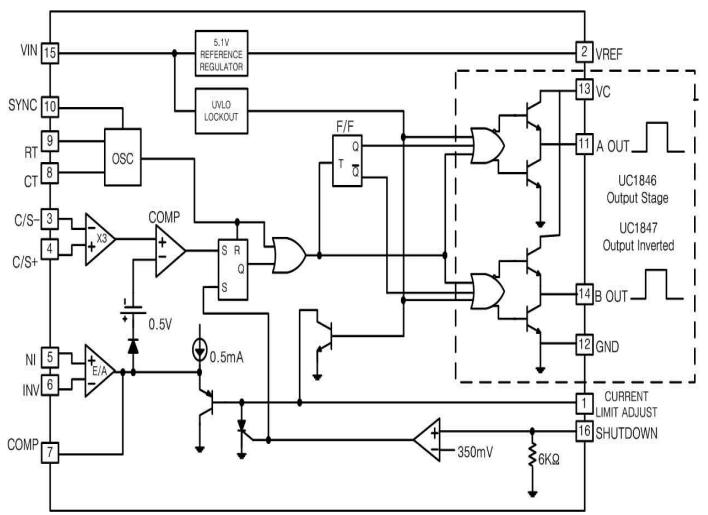

Fig. 2. Block Diagram of PWM-IC

(E/A)의 구조는 트랜지스터로 구성되는데 MOSFET가 턴-온될 때 연산증폭기의 옵셋 전압 은 증가하고 MOSFET의 문턱전압은 외부의 환 경변화로 감소될 수 있다. 시뮬레이션에서 펄스 의 변화는 스위칭 시간, 연산증폭기의 옵셋 전압, 그리고 MOSFET의 문턱전압에 의해 발생된다.

주파수는 등식 (2)에 의해 결정된다.

$$
f=\frac{2 \cdot 2}{R C} \quad(h z)
$$

여기서, $R=10 \mathrm{k} \Omega$ 과 $C=468 \mathrm{nF}$ 를 적용할 경 우 $470 h z$ 의 주파수가 발생된다. 단자 6번과 7번 이 단락(short)되면 5 번 단자의 신호가 출력으로 나오는데 $2.2 \sim 4 \mathrm{~V}$ 가 연산증폭기에 인가된다. 예를 들어, $4 \mathrm{~V}$ 인가 시 비교기(comparator)의 '-' 단자의 입력은 다이오드 $0.7 \mathrm{~V}$ 와 $0.5 \mathrm{~V}$ 전압을 고려할 때 $2.8 \mathrm{~V}$ 가 인가된다. 4 번 단자에 기준전 압을 $2.8 \mathrm{~V}$ 의 $\frac{1}{3}$ 값인 약 $0.93 \mathrm{~V}$ 로 설정할 때 기 준전압보다 큰 값이 인가되면 R/S F/F이 'set' 되어 'OR' 게이트 출력이 'OSC'의 출력 신호가 그대로 넘어간다. 출력단자 11 번과 14 번은 MOSFET의 게이트(gate) 단자에 연결된다.

\section{$2.2 \mathrm{DC} / \mathrm{DC}$ 강압컨버터}

다목적실용위성 3 호의 $\mathrm{DC} / \mathrm{DC}$ 강압컨버터는 태양전지판에서 $60 \mathrm{~V}$ 의 입력을 받아 $5.35 \mathrm{~V}$ 출 력을 요구하는데 Fig. 1의 블록도를 이용하여 SPICE[4]로 시뮬레이션을 수행한 결과 Fig. 3과 같이 인덕터 전류, $\mathrm{PWM}$ 출력파형, 입력전압 및 출력전압을 보여주며, 인덕터 전류는 MOSFET가 턴-오프될 때 시정수 0.24 로 감소됨을 알 수 있 고, 인덕터의 전류와 전압특성을 만족함을 보여 주고 있다.

스위치가 주기 $T$, 통류율 $D$ 로 스위칭될 때 


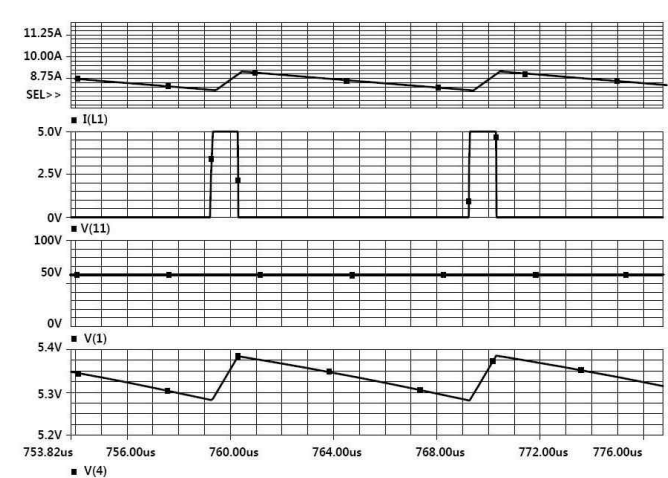

Fig. 3. Inductor current, PWM output waveform, Input voltage of Buck Converter, Output voltage

인덕터 전류 $\left(i_{L}\right)$ 과 인덕터 전압 $\left(v_{L}\right)$ 은 Fig. 3과 같다. 통류율은 턴-온 시간 $\left(t_{o n}\right)$ 과 턴-오프 시간 $\left(t_{o f f}\right)$ 의 전체시간에 대한 턴-온 시간의 비율로 등 식 (3)과 같이 정의된다.

$$
D=\frac{t_{o n}}{t_{o n}+t_{\text {off }}}=\frac{t_{o n}}{T}=t_{o n} f
$$

여기서 $f$ 는 MOSFET의 스위칭주파수이다.

\subsection{1 전류 상승시간: $0 \leq t<D T$}

인덕터 전압 $v_{L}(t)$ 은 등식 (4)와 같이 구할 수 있다.

$$
v_{L}(t)=V_{i}-v_{o}(t)
$$

또한, 인덕터 전류 $i_{L}(t)$ 과 인덕터 전압 $v_{L}(t)$ 과의 관계는 등식 (5)와 같다.

$$
v_{L}(t)=L \frac{d i_{L}(t)}{d t}
$$

등식 (4)과 (5)에서 인덕터에 흐르는 전류의 기 울기는 등식 (6)과 같다.

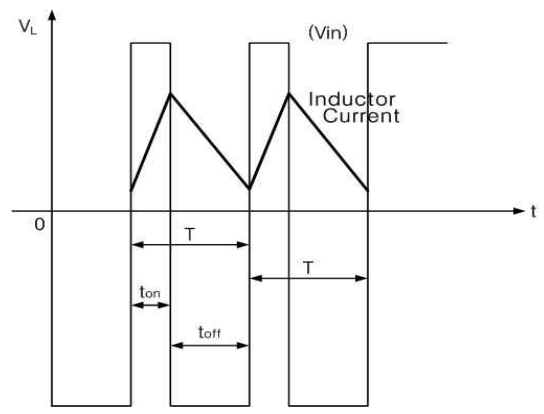

Fig. 4. Inductor voltage and current waveform

$$
\frac{d i_{L}(t)}{d t}=\frac{V_{i}-v_{o}(t)}{L}
$$

DC-DC 컨버터[5,6]의 정상상태에서 출력전압 $v_{o}(t)$ 는 입력전압 $V_{i}$ 보다 작으므로 MOSFET가 $D T$ 구간 동안 입력전원과 도통할 때 인덕터 전 류는 등식 (6)의 기울기로 증가한다.

등식 (6)에서 전류값의 변화는 최대전류와 최 소전류의 차이로 표현되는데 출력전압 $v_{o}(t)$ 에 서 $L, C$ 필터에 의해 교류 성분이 제거된 경우 출력전압은 직류성분인 $V_{o}$ 가 된다. $D T$ 구간 동 안 인덕터 전류 $i_{L}(t)$ 은 등식 (7)과 같이 증가한 다.

$$
I_{\max }-I_{\min }=\frac{V_{i}-V_{o}}{L} \cdot D T
$$

\subsection{2 전류 하강시간: $D T \leq t<T$}

MOSFET가 $(1-D) T$ 도통구간 동안 인덕터 전압 $v_{L}(t)$ 를 등식 (8)과 같이 구할 수 있다.

$$
v_{L}(t)=-v_{o}(t)
$$

인덕터 전류 $i_{L}(t)$ 의 기울기는 $(1-D) T$ 구 간 동안 등식 (9)와 같이 감소한다.

$$
\frac{d i_{L}(t)}{d t}=-\frac{v_{o}(t)}{L}
$$

필터에 의해 교류성분이 제거된 후 직류전압 이 $V_{o}$ 가 되며, $(1-D) T$ 기간 동안 인덕터 전 류 $i_{L}(t)$ 의 변동은 등식 $(10)$ 과 같다.

$$
I_{\min }-I_{\max }=-\frac{V_{o}}{L}(1-D) T
$$

\subsection{3 출력전압: $V_{o}$}

인덕터 전류 $i_{L}(t)$ 는 $D T$ 구간 동안 상승하 고, $(1-D) T$ 구간 동안 하강한다. 정상상태에 서 전류의 상승과 하강폭이 동일하므로 출력전압 의 평균값 $V_{o}$ 는 등식 (11)과 같다.

$$
\frac{V_{i}-V_{o}}{L} D T-\frac{V_{o}}{L}(1-D) T=0
$$

등식 (11)을 정리하면 출력전압은 입력전압에 비례함을 등식 (1)에서 보여주고 있다. 


\section{III. 방사선의 영향}

부품에 미치는 방사선의 영향[1]은 크게 TID(Total lonizing Dose), Displacement Effect (변위 영향), SEE(Single Event Effects)로 나눌 수 있으며 SEE는 SEL(Single Event Latch-up), SEU(Single Event Upset), SET(Single Event Transient), SEGR(Single Event Gate Rupture) 등 으로 나눈다. TID는 핵무기 폭발이나 Van Allan Belts에 형성된 전자나 양성자 혹은 $\mathrm{\gamma}$ 선 및 $\mathrm{x}$ 선 같은 자연환경에서 야기될 수 있으며, SEE는 태 양풍입자(solar particles), 은하우주선(Galactic cosmic rays)으로 야기된다. 수동소자, diode와 bipolar의 구조를 가진 전자소자는 일반적으로 $\mathrm{TID}$ 시험을 수행하고 회로설계에서 $\mathrm{CMOS}$ 와 $\mathrm{Bi}-\mathrm{CMOS}$ (bipolar와 $\mathrm{CMOS}$ 구조를 공유)구조를 가지는 PWM-IC, OP-Amp., 그리고 DRAM 등 메모리소자는 TID 실험과 SEE 실험을 수행한다.

\subsection{TID 시험}

TID 시험절차는 Fig. 5의 Mil-Std-883 Method 1019 를 따르는데 한국항공우주연구원이 개발한 다목적실용위성2호(KOMPSAT-2)에서 적용되는 $\mathrm{K} 2-\mathrm{RAD}-\mathrm{IGG}-0001$ 와 같으며 측정 장비로는 반도 체 소자의 측정 장비인 $\mathrm{HP}$ Semiconductor Parameter Analyzer과 Digital Multimeter를 사 용하였다. 조사시설로는 한국원자력연구원 정읍 방사선연구소의 저준위 방사선 조사실의 코발트 $60\left({ }^{60} \mathrm{Co}\right) \gamma$ y 발생기를 이용한다. 여기서 $\mathrm{\gamma}$ 봉과 조 사시료의 거리가 가까우면 조사시간이 짧아지고 $\gamma$ 봉과 조사시료의 거리가 멀어지면 조사시간을 길게 하여 총 선량이 같게 한다.

조사량은 $2.5,5,7.5,10,20$, 그리고 $30 \mathrm{Krad}$ 까 지 6 등급으로 구분하고 조사율은 $5 \mathrm{rad} / \mathrm{sec}$ 로 조 사한다. 총 조사선량은 선량율(조사율), 거리, 그 리고 시간에 따라 결정되는데, 예를 들어 2.5 $\mathrm{Krad}$ 가 4 회 누적되면 $10 \mathrm{Krad}$ 가 되고 $10 \mathrm{Krad}$ 가 2회 누적되면 $20 \mathrm{Krad}$ 로서 총 선량은 30

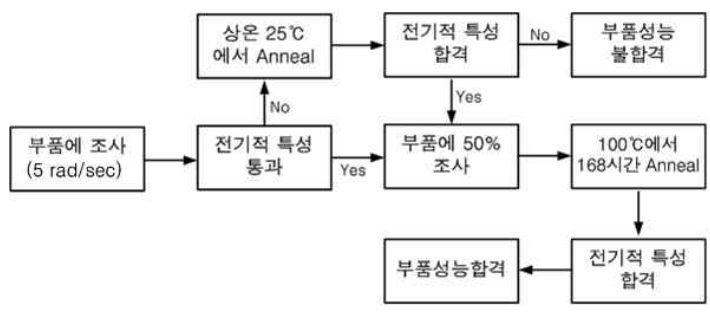

Fig. 5. TID Testing Method and Procedure
$\mathrm{Krad}$ 가 된다. 조사율을 $5 \mathrm{rad} / \mathrm{sec}$ 로 설정시 조사 량이 $2.5 \mathrm{krad}$ 가 되기 위해서는 $500 \mathrm{sec}$ (초) 소요 되고 6 개의 시료를 사용한다. 각 조사횟수가 끝나 고 다음 조사로 들어가기 위해 필요한 조사간격은 30 분이내에 이루어져야 한다. 30 분이 경과되면 시 료의 전기적 특성이 어느정도 복원될 수 있기 때 문이다.

PWM-IC(UC1846, UC2846)의 전기적사양은 Table 1 과 같은데 기준(reference) 출력전압 (output voltage)은 상온 $25{ }^{\circ} \mathrm{C}$ 에서 최소값과 최 대값이 각각 $5.05 \mathrm{~V}$ 와 $5.15 \mathrm{~V}$ 이고, 차단 (shutdown) 문턱전압(threshold voltage)는 최소 값과 최대값이 각각 $250 \mathrm{~V}$ 와 $400 \mathrm{mV}$ 이다. Mil. 급 UC2846의 이용하여 실험한 결과 출력전압은 $30 \mathrm{krad}$ 조사량까지 사양을 만족하나, 문턱전압 은 $5 \mathrm{krad}$ 부터 약간 사양을 벗어나고 있으나 오차 허용범위내에서 전기적특성을 만족한다.

Table 1. PWM-IC Electrical characteristics

\begin{tabular}{|l|c|c|c|c|c|}
\hline \multirow{2}{*}{ PARAMETER } & TEST & \multicolumn{3}{|c|}{ UC1846, 2846 } & UN \\
\cline { 3 - 5 } & CONDITIONS & MIN & TYP & MAX & IT \\
\hline \hline Reference Section \\
\begin{tabular}{c|c|c|c|c|} 
Output \\
Voltage(Vref)
\end{tabular} & $\begin{array}{c}\text { TJ }=25^{\circ} \mathrm{C}, \\
\mathrm{I}_{\mathbf{0}}=1 \mathrm{~mA}\end{array}$ & 5.05 & 5.10 & 5.15 & V \\
\hline $\begin{array}{c}\text { Shutdown Terminal Section } \\
\begin{array}{c}\text { Threshold } \\
\text { Voltage(Vth) }\end{array}\end{array}$ & - & 250 & 350 & 400 & IIV \\
\hline
\end{tabular}

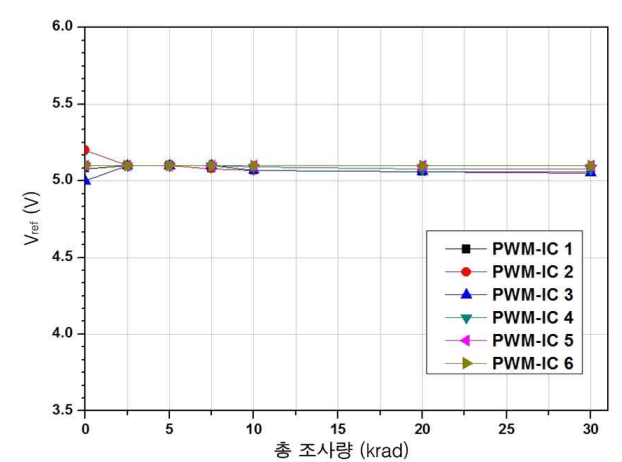

Fig. 6. Reference voltage $\left(V_{\text {ref }}\right)$ vs. dose

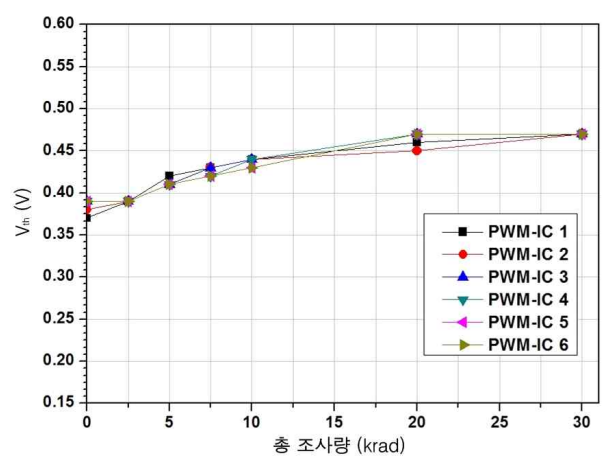

Fig. 7. Threshold voltage $\left(V_{t h}\right)$ vs. dose 


\section{$3.2 \mathrm{SEL}$ 시험}

Figure 8은 SEE (Single Event Effects)실험 절 차를 나타내는데 위성체의 임무와 위치 및 경사 각에 따라 실험을 수행하기 위해 사용되는 입자 의 종류 및 에너지 등을 선택한다.

$\mathrm{SEL}$ 실험에서 PWM-IC 폭의 변화에 따른 출 력전압의 크기를 측정하기 위해 Fig. 9와 같이 구현하였다[7]. 입력에 대한 통류율에 따라 출력 파형은 Fig. 10과 11에서 보여주고 있다. $\mathrm{PWM}-\mathrm{IC}$ 의 입력전압이 $12 \mathrm{~V}$ 에서 통류율이 0.2 와 0.4 일 경우 출력전압이 각각 $2.4 \mathrm{~V}$ 와 $4.8 \mathrm{~V}$ 가 되 어 이론치와 일치함을 알 수 있다.

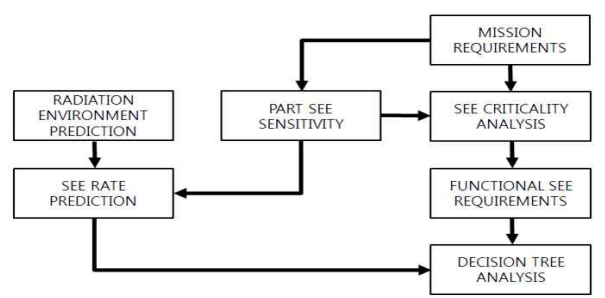

Fig. 8. SEE test (ASTM F1192)

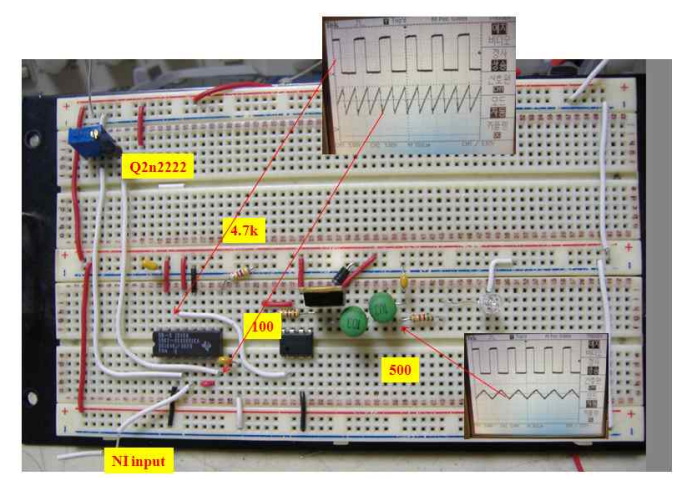

Fig. 9. Implementation of DC-DC converter with PWM-IC

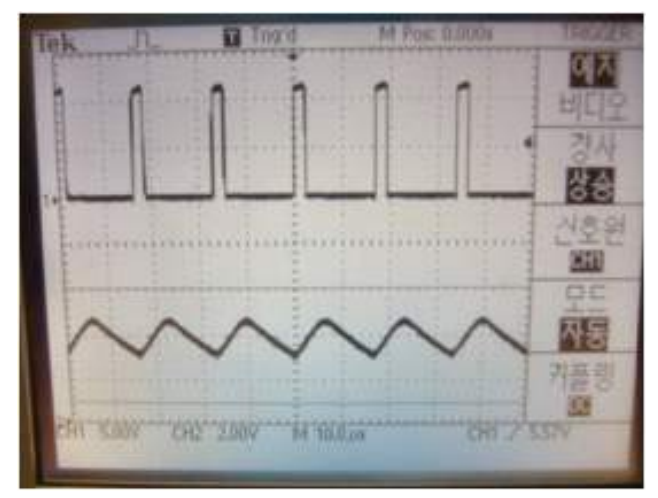

Fig. 10. Output voltage for $D=0.2$

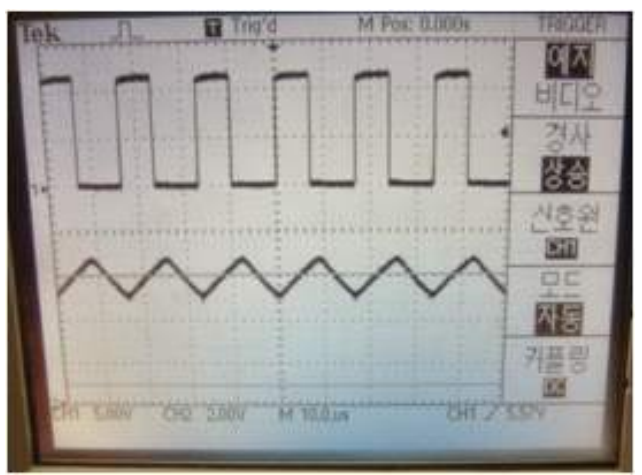

Fig. 11. Output voltage for $D=0.4$

PWM-IC의 SEL 실험을 위해 NASA 등 산업 체가 많이 이용하고 세계적으로 가장 권위있는 미국 Texas A\&M University Cyclotron Facility 의 중이온가속기에서 에너지가 $15 \mathrm{MeV} / \mathrm{u}$ 인 중이온 4 종 $(\mathrm{Kr}, \mathrm{Xe}, \mathrm{Ho}, \mathrm{Au})$ 을 bare chip 상태의 시료에 조사하였다. 실험결과 짧은 시간에 $\mathrm{PWM}$ 파형에 latch-up이 발생하지 않고 1 개 시료 당 최소 12 분 20 초, 최대 50 분 45 초 동안 중이온을 조사하여 Table 3과 같이 $\mathrm{PWM}$ 파형의 천이 (transient)가 발생되었으며 LET (Linear Energy Transfer)별 cross section은 Fig. 13과 같다. LET 가 $40,57,69\left(\mathrm{MeV} / \mathrm{mg} / \mathrm{cm}^{2}\right)$ 의 cross section값은 2 개 값을 평균하여 도시하였다.

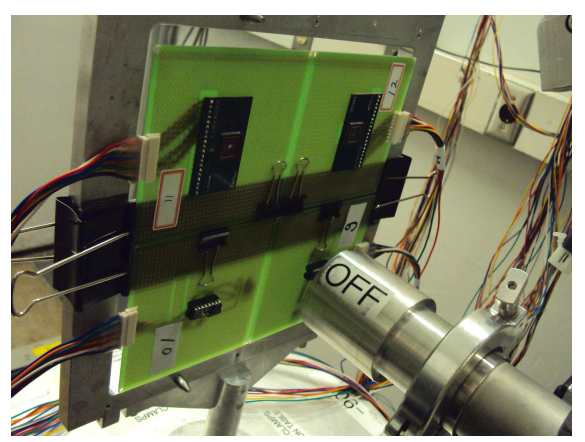

Fig. 12. Heavy ions test at A\&M Univ. Cyclotron Facility, USA

Table 2. Ion specifications of $15 \mathrm{MeV} / \mathrm{u}$ energy at Texas A\&M Univ./ Radiation Effects Facility

\begin{tabular}{|c|c|c|c|c|}
\hline Ion & Mass(u) & $\begin{array}{c}\text { Total } \\
\text { Energy(MeV) }\end{array}$ & $\begin{array}{c}\text { Initial } \\
\text { LET(air) }\end{array}$ & $\begin{array}{c}\text { LET at } \\
\text { Bragg Peak }\end{array}$ \\
\hline \hline${ }^{84} \mathrm{Kr}$ & 83.912 & 1259 & 26.6 & 41.4 \\
\hline${ }^{129} \mathrm{Xe}$ & 128.905 & 1934 & 49.3 & 63.4 \\
\hline${ }^{165} \mathrm{Ho}$ & 164.930 & 2474 & 66.7 & 79.2 \\
\hline${ }^{197} \mathrm{Au}$ & 196.967 & 2954 & 82.8 & 93.5 \\
\hline
\end{tabular}


Table 3. SEL transients of PWM-IC of UC-2846

\begin{tabular}{|c|c|c|c|c|c|}
\hline $\begin{array}{l}\text { SA } \\
\text { MP } \\
\text { LE }\end{array}$ & $\begin{array}{c}\mathrm{LET} \\
\left.(\mathrm{MeV} / \mathrm{mg} / \mathrm{cm})^{2}\right)\end{array}$ & $\begin{array}{c}\text { Fluence } \\
\text { (ions/crif) }\end{array}$ & $\begin{array}{c}\text { Cross } \\
\text { Section(cir) }\end{array}$ & SEL Event & 비 고 \\
\hline 1 & 40 & $1.50 \times 10^{9}$ & $6.67 \times 10^{-10}$ & 발생없음 $(10 \% \downarrow)$ & 24 분 06 조 \\
\hline 2 & 40 & $1.83 \times 10^{9}$ & $5.46 \times 10^{-10}$ & 발생없음(10\%】) & 50 분 45 초 \\
\hline 3 & 57 & $2.85 \times 10^{9}$ & $3.51 \times 10^{-10}$ & 발생없음(10\%\) & 49 분28초 \\
\hline 4 & 57 & $3.03 \times 10^{9}$ & $3.30 \times 10^{-10}$ & 발생없음(10\%】) & 43 분55초 \\
\hline 5 & 69.1 & $7.10 \times 10^{8}$ & $1.41 \times 10^{-9}$ & 발생없음(7\%】) & 23 분 40 조 \\
\hline 6 & 69.1 & $5.34 \times 10^{8}$ & $1.87 \times 10^{-9}$ & 발생없음(5\%।) & 12 분20초 \\
\hline 7 & 90 & $4.40 \times 10^{8}$ & $2.27 \times 10^{-9}$ & 발생없음 $(10 \% \downarrow)$ & 39분38초 \\
\hline
\end{tabular}

(비고: $10 \% \downarrow$ 는 PWM 파형주파수가 $10 \%$ 감소함을 의 미하고, 24분 06초는 flux 인가시간을 나타냄)

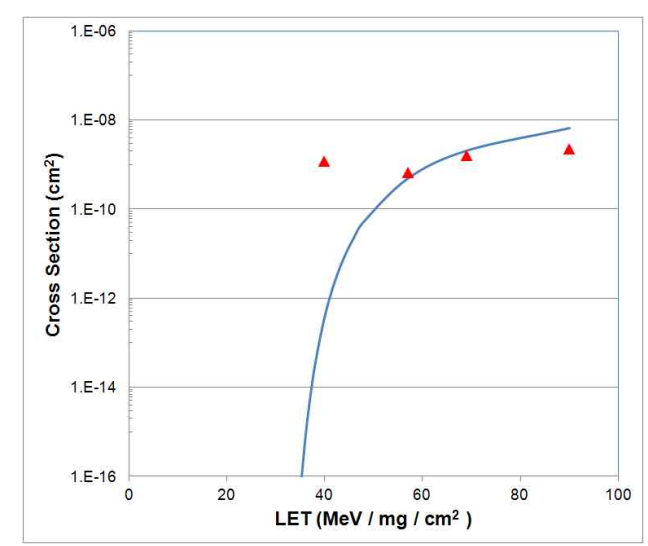

Fig. 13. Cross section vs. LET of PWM-IC $\left(\mathbf{\Delta}\right.$; transient capture, $\operatorname{LET}_{\text {th }}=36$ $\mathrm{MeV} / \mathrm{mg} / \mathrm{cm}^{2}$ )

중이온의 Flux(빔의 세기)를 설정할 때 Flux의 세기를 증가하면 PWM 파형의 변화시간이 단축 되고, Flux 세기를 감소하면 시간이 중가되므로 Flux 세기를 적절히 설정한 후 조사하여 Fluence 값을 얻는다. 여기서 cross section은 입자 (particle) 들 간에 반응하는 정도를 나타내는 지 표인데 사건이 한번 일어나는 시간을 $\mathrm{T}(\mathrm{sec}$.) 라 고 하면 cross section[8,9]은 등식 (12)과 같이 표 현된다.

$$
\sigma\left(\mathrm{cm}^{2}\right)=\frac{1}{\text { fluence }}\left(\text { ions } / \mathrm{cm}^{2}\right)
$$

Figure 13의 cross section 값은 $1 \times 10^{-8}\left(\mathrm{~cm}^{2}\right)$ 미만값으로 수렴함을 보여주고 있다.

\section{IV. 결 론}

설계에서 Bi-CMOS 구조를 가지는 PWM-IC에 대하여 코발트 $60\left({ }^{60} \mathrm{Co}\right)$ 감마발생기를 활용하여 $30 \mathrm{krad}$ 조사량까지 TID 실험을 수행하였으며,
PWM-IC의 SEL 평가를 중이온가속기의 에너지 $15 \mathrm{MeV} / \mathrm{u}$ 에서 중이온 4 종 $(\mathrm{Kr}, \mathrm{Xe}, \mathrm{Ho}, \mathrm{Au})$ 을 이용하여 bare chip으로 $\mathrm{LET}\left(\mathrm{MeV} / \mathrm{mg} / \mathrm{cm}^{2}\right)$ 별 cross section $\left(\mathrm{cm}^{2}\right)$ 실험을 성공적으로 수행하였 다. 향후, 본 연구결과를 바탕으로 차세대 위성체 의 부품국산화 추진에서 내방사선 특성 및 평가 기술로 활용될 수 있고 우주용 전자부품 영향평 가 기술개발의 기반을 마련하였다고 본다.

\section{후 기}

본 연구는 교육과학기술부 우주 연구개발 프 로그램 지원으로 이루어 졌습니다.

\section{References}

1) P. C. Adell et $\mathrm{Al}$, "Total-Dose and Single-Event Effects in DC/DC Converter Control Circuitry," IEEE Transactions Nuclear Science, Vol. 50, No. 6, December, 2003

2) Y. H. Lho, "A Study on the Design of Voltage Mode PWM DC/DC Power Converter," Journal of the Korean Society for Railway, 14(5), October, 2011

3) Datasheet of UC 1846, 2846, Texas Instruments, 2002

4) Cadence Design Systems, "SPICE reference Guide," San Jose, CA, Cadence Design Systems, Inc., 2004

5) E. C. Roh, K. B. Jung, N. S. Choi, "Power Electronics," Moon Woon Dang, pp. 190 218, 1997 (in Korean)

6) S. H. Lee, J. Y. Jung, "Power Electronics Engineering," Seoul, Hyung Seol Publications Inc. pp. 147 153, 2006

7) Y. H. Lho, "Implementation of DC/DC Power Buck Converter Controlled by Stabel PWM," Journal of Institute of Control, Robotics and Systems (2012) 18(4) pp. 371-374

8) N. W. Van Vonno, L. G. Pearce, GM Wood et. al, "Total Dose and Single Event Testing of a Hardened Single-Ended Current Mode PWM Controller," NSREC, July, 2010

9) A Technical Report, "Development of Evaluation Technology of SEL Effects on Electronic Component for SPACE," National Research Foundation of Korea (2011) (in Korean) 